\title{
Initial and final position for adverbial clauses in English: the constructional basis of the discursive and syntactic differences ${ }^{1}$
}

JEAN-CHRISTOPHE VERSTRAETE

\section{Abstract}

This study argues that adverbial clauses in initial position constitute a distinct construction type within the domain of clause combining in English, and that their specific constructional features can help to explain the oftenobserved correlation between initial position, discourse-organizing function and subordination. Specifically, it is argued that initial adverbial clauses can be characterized in terms of two constructional parameters, one relating to the internal structure of the adverbial clause, and another relating to its status with respect to the main clause. It is shown that these features can explain why initial position typically goes hand in hand with discourseorganizing function and why it can be used as a criterion for subordinate status. In addition, it is also shown that this approach can provide descriptive corrections to a number of traditional views, such as the assumed general correlation between final position and local function, and the apparently conflicting definitions of subordination in terms of relative prominence and integration.

\section{Introduction}

Adverbial clauses ${ }^{2}$ in initial position in English, like the after clause and the although clause in (1) and (2) below, have a number of well-known discursive and syntactic characteristics. In terms of discursive function, for instance, they are distinct from their counterparts in final position in that they usually have discourse-organizing rather than local functions, such as linking back to the preceding discourse or introducing new frames for upcoming discourse (Thompson 1985; Ramsay 1987; Givón 1990; Ford 1993). In terms of syntax, on the other hand, the potential to occur in initial position is often used as a criterion for distinguishing coordinate from subordinate constructions (Greenbaum 1969; Quirk et al. 1985). 
(1) As well, there had been a strike by the drinkers of the town against a beer price rise. Miss O'Mara of O'Mara's Hotel (her brother was chairman of the Brisbane Amateur Turf Club and the Queensland legal man for John Wren) told me that my father had been leader for the five hotel-keepers of the town and was fearless and wonderful. After the strike was over, his business did suffer and, as my mother did not like the environment of a hotel for bringing up children, it was decided to change to some other type of business. (IC) $)^{3}$

(2) Accompanying Mangels on part of his journey to complete World Safari II was Melbourne model Judy Green, who was seriously injured with Mangels in a road accident in South America. Although the tone of the expedition was soured by the accident, the movie was completed and classified a success by film patrons. (IC)

In this study, I will argue that adverbial clauses in initial position constitute a distinct construction type within the domain of clause combining in English, and that their specific constructional characteristics can be used to explain the discursive and syntactic features traditionally associated with them. More specifically, I will show that initial adverbial clauses can be characterized in terms of two grammatical parameters, both of which relate to aspects of the illocutionary structure of the complex sentence construction.

The first parameter relates to the INTERNAL illocutionary structure of the initial clause, more specifically its behaviour with respect to the basic encoders of illocutionary force. Clause combinations in English can be subdivided depending on whether the secondary clause ${ }^{4}$ allows the full range of basic clause types (declarative, interrogative, imperative) or is restricted to the declarative. For clauses in final position, the distinction is basically a matter of the type of conjunction, some allowing all basic clause types, others being restricted to the declarative, and still others being ambiguous between the two. Initial clauses, on the other hand, inherently take one side of the distinction: they do not allow any clause type beyond the declarative, irrespective of the type of conjunction that is used.

The second parameter relates to the EXTERNAL relation of the initial clause to the illocutionary structure of the main clause. Clause combinations in English can also be subdivided depending on whether the secondary clause falls within the scope of the illocutionary operators of the main clause or not. For final clauses, this distinction is encoded by intonation, but it can also be related to certain types of conjunctions. Initial clauses, on the other hand, again take one side of the distinction: they generally do not fall within the scope of the illocutionary operators of the main clause, independently of the type of conjunction that is used. 
These two parameters will be elaborated in sections 2 and 3 of this study. I will first indicate the general relevance of each parameter for the analysis of clause combining in English, and then show its more specific relevance for the analysis of initial and final adverbial clauses. Section 4 will be devoted to the relation between the two parameters, showing that initial adverbial clauses single out one specific constructional slot in the whole domain of clause combining. In sections 5 and 6 , finally, I will show how these parameters can help to explain the discursive and syntactic characteristics that have traditionally been associated with initial position.

Before introducing the relevant constructional parameters in sections 2 and 3, I will first discuss the discursive and syntactic characteristics traditionally associated with initial adverbial clauses in some more detail.

\subsection{Discursive potential}

It has often been argued that initial adverbial clauses have a very different discursive function from their final counterparts (see, for instance, Thompson 1985; Ramsay 1987; Givón 1990: 844-847; Ford 1993: $26-$ 62). Adverbial clauses in final position often have a local function, elaborating on the State of Affairs (henceforth SoA) of their main clause by specifying reasons, temporal circumstances, etc. Adverbial clauses in initial position, on the other hand, usually do not have such a strictly local function, but take up wider discourse-organizing functions, by specifying a new frame for upcoming discourse or linking back to preceding discourse. Compare, for instance, examples (3) and (4):

(3) All week we were unable to ski Gers, a steep bowl with Flaine's best powder runs, because of avalanche risk. On our last day it opened as we were passing. We found a virgin slope, blasted by the dawn patrollers and ours for the taking. (CB)

(4) My own illusion in joining the fairground was multiple wrongth. I'd assumed that a travelling fair is jolly, colourful gay - wrong. It's a million laughs a minute - mistake. After only a cup of tea I slogged with a gorilla called Big Chas and his mate Ern erecting broadwalks and canvases, hauling generators and winching struts and wooden walls. I fetched and carried. Francie wrapped my hands in oily cloths to keep me going. As the fairground took shape I began to peter out so they put me on netting the dodgem cars. God did great making mankind, but $\mathrm{He}$ was all thumbs when $\mathrm{He}$ came to antique dealers. I felt useless. (CB) 
The final as clause in (3) has a purely local function, specifying the temporal circumstances of the SoA described in the main clause. The initial as clause in (4), on the other hand, has wider discursive links beyond its main clause: the as clause in (4) plays a role in the organization of discourse, because it serves as a discursive "bridge" (Givón 1990: 847) between the preceding discourse, which describes the buildup of the fairground, and the following discourse, which returns to the main thematic line of the narrative, describing the unsuitability of the speaker for this type of work.

In the following sections, I will show how the difference in discursive potential associated with initial and final position can be explained as a consequence of the specific constructional properties of initial adverbial clauses. I will also argue, however, that some of these constructional properties can equally occur with particular types of final clauses, with the same discursive effects. In this sense, the crucial factor for local versus wide discursive function does not seem to be the distinction between initial and final position as such, as has traditionally been claimed, but rather the cluster of grammatical characteristics that motivate wide discursive function, which are typically but not exclusively associated with initial position.

\subsection{Criteriality for subordination-coordination}

Another characteristic that has traditionally been associated with initial position is the distinction between subordination and coordination (Greenbaum 1969: 31; Quirk et al. 1985: 927-928; Halliday 1994 [1985]: 222-223). The potential to be moved into initial position can be used as a criterion for distinguishing between coordinate and subordinate constructions: clauses introduced by subordinating conjunctions can be moved into initial position, whereas clauses introduced by coordinating conjunctions cannot. Compare, for instance, examples (5) and (6):

(5) a. Ovulation rates of 2.5-year-old ewes increased only when $500 \mathrm{~g}$ of lupins per head per day were fed, whereas older ewes showed increases in ovulation at both feeding rates. (IC)

b. Whereas the 50s demanded that we co-operated with one another for little reward, the 80 s have seen whole sections of society become an irrelevance to many social and political processes. (IC)

(6) a. About 100 patients left the hospital yesterday, but the critically ill and those who were unable to be moved stayed. (IC) 


\section{b. *But the critically ill and those who were unable to be moved stayed, about 100 patients left the hospital yesterday.}

Both whereas in (5) and but in (6) encode roughly similar relations of contrast between the clauses they combine. The difference between the two is that the clause introduced by whereas can be moved into initial position, whereas the clause introduced by but cannot. This has traditionally been used as one of the arguments for classifying whereas as a subordinating conjunction and but as a coordinating one. The question is, of course, WHY this should be used as a criterion for the distinction between coordination and subordination. In the following sections, I will argue that the specific constructional characteristics of initial position provide a functional motivation for the relation between preposing and subordination. In addition, I will also show how these features can help to shed some more light on a number of apparently conflicting definitions of subordination.

\section{The internal illocutionary structure of the secondary clause}

\subsection{General relevance}

Complex sentence constructions in English can be formally classified according to whether the secondary clause allows all basic clause types (declarative, interrogative, and imperative) or whether it remains restricted to the declarative (compare Foley and Van Valin 1984: 239-240; Hengeveld 1998 for similar arguments). I will argue that the functional value of this distinction is related to the illocutionary status of the secondary clause within the complex sentence construction. Compare, for instance, examples (7) and (8):

(7) a. John offered Mary the money, but she refused it.

b. John offered Mary the money, but didn't she refuse it?

c. John offered Mary the money, but don't ever think that she will accept it.

(8) a. Mary refused the money when John offered it to her.

b. *Mary refused the money when didn't John offer it to her?

c. *Mary refused the money when do keep in mind that John offered it to her.

The but clause in (7a) and the when clause in (8a) are formally both declarative, but this declarative has an entirely different value for the two examples. The declarative in (7a) potentially contrasts with different basic 
clause types such as the interrogative in (7b) and the imperative in (7c), whereas the declarative in (8a) does not contrast with any other basic clause type, as shown by the unacceptability of the interrogative in (8b) and the imperative in (8c). Thus, the but clause in (7) allows the full paradigm of basic clause types, whereas the when clause in (8) remains restricted to the declarative.

This formal distinction can be related functionally to the illocutionary status of the secondary clause within the complex sentence construction. The different basic clause types encode a range of interactional configurations that form the basis for the illocutionary force of a particular structure. In this sense, paradigmatic availability of the full range of basic clause types for the but clause in (7) reflects that this clause functions as a speech act of its own, just like the main clause. Paradigmatic absence of the full range of basic clause types for the when clause in (8), on the other hand, reflects that it does not function as a speech act within the complex sentence construction. The when clause in (8a) is formally declarative, but functionally this declarative cannot be regarded as encoding, for instance, an assertive speech act: if it really did encode an assertive speech act, we would also expect this assertion to be codable as a "rhetorical" interrogative (*when didn't John offer it to her) or imperative (*when do keep in mind that John offered it to her). Instead of encoding an assertive speech act, the formal occurrence of the declarative in (8a) can be explained as a typical switch to the unmarked option of a paradigm in a context of neutralization, in this case neutralization of illocutionary force, as encoded by the paradigm of basic clause types (see further in Verstraete [2004] for more details and comparative Germanic evidence for this analysis).

Thus, there is a basic functional distinction between clause combinations where both the main clause and the secondary clause have their own illocutionary value (which will be called [+ Speech Act]), and clause combinations where only the main clause has its own illocutionary value, and the secondary clause does not (which will be called [- Speech Act] see further in section 5.1 on the functional characterization of this construction). The distinction between [+ Speech Act] and [- Speech Act] is linked to a number of overt markers, more specifically lexical (classes of conjunctions) and syntactic (relative position of main clause and secondary clause).

First of all, there is a category of conjunctions that is like the but clause in (7), in that they structurally allow different basic clause types and therefore have their own illocutionary value within the complex sentence construction: this is the case for the traditional coordinate conjunctions and, for, but, and or, illustrated in (9)-(11). In each of these cases, the second- 
ary clause constitutes a second speech act within the complex sentence construction, linked to the main clause either in a relation of addition (9), alternation (10), or justification (11).

(9) I said, No! I want you to leave me. I don't want you inside me. I don't want you beside me. I hate this room. I don't want to be here and don't come looking for me. (IC)

(10) They've suddenly gone up, remember I told you they had gone up. Yeah, I know that, the first price has gone up, but does that mean all of them go up. (IC)

(11) Naturally, this provoked considerable mirth in the audience, for who in the academy still believes in either the West's achievements or its honesty? (CB)

Other conjunctions are like the when clause in (8), in that they structurally do not allow any basic clause type beyond the declarative and therefore do not constitute a speech act within the complex sentence construction: this is the case for traditional subordinate conjunctions like when, while, whereas, after, before, so that, ${ }^{5}$ since, if, or as, illustrated in (12)-(13).

(12) a. I decided that I ought to be feeling fit for the challenge. As I didn't have time to go to the gym before I left, I had to jump up and down in my living room for half an hour in front of a video of Anthea Turner grinning insanely in a pink leotard instead. (CB)

b. *As did(n't $)^{6}$ I have time to go to the gym before I left, I had to jump up and down in my living room for half an hour.

(13) a. Der Spiegel also says it has the text of the report made by the KGB officers in Magdeburg after they had burned the bones. (CB)

b. *Der Spiegel also says it has the text of the report made by the KGB officers in Magdeburg after had(n't) they burned the bones.

Two conjunctions, finally, allow both construction types: because and although can either behave like the but clause or like the when clause, depending on a number of factors. In some cases, the determining factor is the meaning of the interclausal relation: thus, for instance, a because clause does not allow nondeclarative clause types if it expresses a purely causal relation, as in (14), whereas it does if it serves to justify some aspect of the speech act of the main clause, as in (15) (see further Verstraete [1998] on this type of structure). 
(14) a. According to a spokesperson he does have tendinitis. It happened because he uses the muscles in his strumming arm too much. (CB)

b. *It happened because doesn't he use the muscles in his strumming arm too much.

(15) I believe it's time "Saint" George Galloway was officially canonised preferably using an Iraqi supergun. His intentions must be honourable because who in their right mind would go to Baghdad right after the Gulf War, in which British troops died, and praise the lunatic responsible for starting it? (CB)

Apart from such semantic factors, another factor that determines the precise value of $[+/-$ Speech Act $]$ for these conjunctions is the relative position of main clause and secondary clause, as will be shown in the following section.

\subsection{The relevance of initial position}

Initial adverbial clauses have a special status with respect to the parameter of $[+/-$ Speech Act], in that they always take the value $[-$ Speech Act]. ${ }^{7}$ Formally, initial clauses can never take any basic clause types beyond the declarative, as shown in (16)-(18) below. Functionally, therefore, this restriction implies that they do not have any illocutionary value within the complex sentence construction in which they occur.

(16) a. After the strike was over, his business did suffer and, as my mother did not like the environment of a hotel for bringing up children, it was decided to change to some other type of business. (IC)

b. *After was(n't) the strike over, his business did suffer.

(17) a. The Iraqis have done exactly what they did during the IranIraq war, which is to create row after row of bunkers and trenches and just lines of defense that they can fall back on. If one line of defense fails, then they can always pull back to the next one. (CB)

b. *If does(n't) one line of defense fail, then they can always pull back to the next one.

(18) a. Whereas Thompson still receives a substantial income from commercial interests, Kruger has to go out to work for a living to support his wife and one-year-old daughter. (CB)

b. *Whereas does(n't) Thompson still receive a substantial income from commercial interests, Kruger has to go out to work for a living to support his wife and one-year-old daughter. 
The inherent association between initial position and [- Speech Act] is actually confirmed by the behavior of 'ambiguous' conjunctions that allow both [+ Speech Act] and [-Speech Act], like because and although. Such conjunctions easily allow nondeclarative clause types when they introduce a secondary clause in final position, as shown in (15) above and in (19a) and (20a) below, but they do not allow any nondeclarative clause types when moved to initial position, as illustrated by the contrast in acceptability between (19a)-(19b) and (20a)-(20b).

(19) a. The shamed ex-spy, freed early after serving 14 years for offering secrets to the Russians, said: "I want to chill out and get used to freedom. Then I want to look for a job. I would consider anything, even being a postman - after all, a job's a job. I have to consider anything because who is going to employ me?" (CB)

b. *Because who is going to employ me, I have to consider anything.

(20) a. One nice touch is that they named one of the companies "Sackson," although why did it have to be one of the little cheap ones? ${ }^{8}$ (IC)

b. *Although why did it have to be one of the little cheap ones, one nice touch is that they named one of the companies "Sackson."

Thus, the behavior of ambiguous conjunctions like because and although clearly shows that the restriction on nondeclarative clause types is a property of the initial position as such rather than any specific conjunction, and that initial position is therefore inherently associated with a value of [-Speech Act]. This is further confirmed by the behavior of conjunctions like for or but, which allow only a value of [+ Speech Act], and accordingly cannot occur in initial position. Table 1 below summarizes the general relevance of the parameter of $[+/-$ Speech Act $]$ for the domain of clause combining, as well as the specific status of initial position.

\section{The relation of the secondary clause to illocutionary operators in the main clause}

\subsection{General relevance}

The second parameter that defines initial adverbial clauses as a separate construction type does not concern the INTERNAL illocutionary structure of the secondary clause, but rather its EXTERNAL relation to the illocu- 
Table 1. The parameter $[+/-$ Speech act $]$

\begin{tabular}{|l|c|c|}
\hline \multirow{2}{*}{} & \multicolumn{2}{|c|}{ Speech act } \\
\cline { 2 - 3 } & Initial position & Final position \\
\hline and, but, for, or & & + \\
\hline although, because & - & $+/-$ \\
\hline after, as, before, if, since, so that, when, while & - & - \\
\hline
\end{tabular}

tionary structure of the main clause. It is a well-known fact that clause combinations in English can be formally subdivided according to whether the secondary clause can fall within the scope of operators like interrogation and modalization in the main clause or not: in fact this is the basic criterion behind Greenbaum's (1969: 15-25) and Quirk et al.'s (1985: 1070-1072) distinction between "adjunct" and "disjunct" clauses. I will argue that the functional value associated with this distinction relates to whether the illocutionary value of the main clause applies to the complex formed by main clause and secondary clause or whether it remains restricted to the main clause. Compare, for instance, examples (21) and (22):

(21) a. He discovered the body before the police arrived.

= "that is when he discovered the body"

b. Did he discover the body before the police arrived?

= "is that when he discovered the body?"

c. He must have discovered the body before the police arrived. $=$ "that must have been when he discovered the body"

(22) a. He discovered the body in the attic, although the police had already searched the building.

b. Did he discover the body in the attic, although the police had already searched the building?

c. He must have discovered the body in the attic, although the police had already searched the building.

The difference between clause combinations like (21) and (22) comes to the surface very clearly in contexts of interrogation and modalization of the main clause. In (21), the secondary clause can function as the focus of the interrogative and modal operators, with the rest of the clause complex as a presupposition. Thus, what is interrogated and modalized in (21b) and (21c) is not whether or not the body was discovered, but rather the time when this happened: the speaker presupposes that the body was dis- 
covered at some time, and asks whether (21b) or confidently infers that (21c) this happened before the police arrived. In structures like (22), on the other hand, the secondary clause cannot function as the focus of interrogation or modalization, with the rest of the clause complex as presupposition. The structures in (22b) and (22c) cannot be interpreted in parallel with (21b) and (21c), viz. as presupposing that the body was discovered in the attic and questioning (22b) or confidently inferring (22c) that this occurred in spite of the previous searches of the building by the police. What is questioned and modalized in (22b) and (22c) is whether or not the body was discovered: the focus of interrogation and modalization in this type of structure remains restricted to the main clause, and does not extend to the secondary clause.

Given that the operators whose scope is tested in (21)-(22) together serve as the basic syntactic encoders of illocutionary force (see further in Verstraete 2001), the functional value of this distinction relates to whether the secondary clause in the complex sentence construction falls within the scope of the illocutionary value of the main clause. In structures like (21), the illocutionary operators in the main clause have scope over the entire complex formed by main clause and secondary clause, as shown by the fact that they can extend their focus to the secondary clause. In structures like (22), on the other hand, the illocutionary operators in the main clause have scope only over the main clause and do not extend to the secondary clause, as shown by the fact that the secondary clause in these structures cannot serve as focus of these operators.

Thus, there is a basic functional distinction between clause combinations where main clause and secondary clause form one single complex that falls within the scope of the illocutionary operators of the main clause (a value of $[+$ Scope], which will be referred to as "integrated" construal in what follows), and clause combinations where the secondary clause does not fall within the scope of the speech-act value of the main clause (a value of [-Scope], which will be referred to as "detached" construal). Like the distinction between the different values for the parameter of $[+/-$ Speech Act], the distinction between [+ Scope] and [-Scope] is linked to a range of overt markers, including lexical (specific categories of conjunctions), intonational (intonation unit distribution) and syntactic (relative position of main clause and secondary clause).

First of all, there are a number of conjunctions that inherently take detached construal (-Scope): this is the case for the traditional coordinators and, or, but, for, as well as for conjunctions with inherently contrastive meaning like although and whereas. With these conjunctions, the illocutionary operators in the main clause cannot take the secondary clause as their focus, while at the same time taking the main clause as 
presupposition. ${ }^{9}$ Compare, for instance, the because clause in (23a) with its for counterpart in (24a). The because clause in (23a) can be said to fall within the scope of the illocution of the main clause, because it serves as the focus of the conclusion encoded by must, with the main clause as a presupposition: the speaker in (23a) presupposes that the fans turned up and concludes that they did so because they knew the team was at the hotel. The for clause in (24a), on the other hand, does not fall within the scope of the illocution of the main clause, because it cannot serve as focus of the conclusion encoded by must: in (24) the fact that the fans turned up cannot be presupposed by the speaker, but is itself the focus of the conclusion. This distinction in terms of scope structure is further reflected in the fact that the because clause in (23) allows a number of specific syntactic focus-presupposition configurations like cleft constructions and wh questions, illustrated in (23b) and (23c), whereas the for clause does not allow these configurations, as shown by the unacceptability of (24b) and (24c).

(23) a. Some of the girls were so drunk that I was scared they would fall off. That's when I decided to call security. They must have turned up because they knew the England team were staying here. $(\mathrm{CB})$

b. It is because they knew the England team were staying there that they turned up.

c. Why did they turn up?

(24) a. They must have turned up, for they knew the England team were staying there.

b. *It is for they knew the England team were staying there that they turned up.

c. $\quad \neq$ Why did they turn up?

Conjunctions that are not exclusively associated with detached construal can all be construed as either detached ( - Scope) or integrated (+ Scope). In these cases, the factors that determine the value of the scope parameter are patterns of polysemy for the conjunctions, the intonational structure of the complex sentence construction, and the relative position of main clause and secondary clause within the construction. For a number of conjunctions, the constructional properties of the complex sentence are split out according to the semantic structure of the conjunction: specifically, the detached construction is associated with those senses that semantically correspond to conjunctions that allow only detached construal, like whereas, but, or for. This is the case for conjunctions like when, while, as, and since: the contrastive senses (for when and while) and the justificational senses (for as and since) are associated with detached construal, 
whereas the temporal senses can have either construal (see further in Traugott and König [1991] on the polysemy patterns, and Goethals [2002] on their constructional features). Compare, for instance, the temporal sense of while in (25) with its contrastive sense in (26). A temporal while clause can easily fall within the scope of the illocutionary operators in the main clause, as shown by the fact that it can be focused by an interrogative, as in (25a), and can serve as focus of a cleft construction, as in (25b). A contrastive while clause, on the other hand, cannot fall within the scope of the illocutionary operators in the main clause. This is reflected in the fact that it cannot be focused by an interrogative, as illustrated in (26b), where the question focuses on the falling of the yen and not on the contrast with the dollar, as well as in the fact that use of a cleft construction is not possible with the contrastive interpretation but shifts it to a temporal one, as in (26c).

(25) a. I think it's very important to measure when and where things occurred. Did they occur when you're a young person, in your formative years, or did they occur while you were a senior offcial in the federal government? (CB)

b. It is while you were a senior official in the federal government that these things occurred.

(26) a. Japanese stocks fell below 1987 Black Monday levels, while the US dollar picked up nearly a half yen in Tokyo trading today. (CB)

b. Did Japanese stocks fall below 1987 levels, while the US dollar picked up half a yen?

c. $\neq$ It is while the US dollar picked up nearly half a yen that Japanese stocks fell below 1987 trading levels.

For the remaining cases, that is, conjunctions for which the distinction between detached and integrated construal is not associated with specific polysemy patterns, the $[+/-$ Scope $]$ distinction is directly encoded by intonational means, more specifically the distribution of intonation units over the complex sentence construction: encoding of the secondary clause as a separate intonation unit marks a value of [-Scope], whereas integration into the intonation unit of the main clause implies a value of $[+$ Scope $]$. The reason why the intonation unit is the relevant formal factor is of course that intonation units form the domain of focus-presupposition organization, which as argued above is the basic criterion to test the scope structure of a particular construction. Focuspresupposition organization operates within intonation units, in which the focus is assigned by means of the nuclear accent and the rest of the material in the intonation unit acquires presupposed status (Halliday 
1967a: 199-211; Halliday 1967b: 20-24). In this sense, integration of the secondary clause into the intonation unit of the main clause can be regarded as a necessary prerequisite for taking the value [ + Scope], whereas intonational detachment of the secondary clause implies a value of [- Scope]. Compare, for instance, the structures in (27) and (28) below:

(27) why didn't she have jlabs\# I don't have a cllue\# [...] right, when I went to T/urkey\#, I had three jabs before I went aw $\backslash$ ay\#, and every two days I took two tlablets\# (IC) ${ }^{10}$

(28) do you wanna ... erm go for a qluick one\# before it clloses\#. yleah\#. before it clloses\# (IC)

Given that the domain for focus-presupposition structure is the intonation unit, focused status for a secondary clause in a complex sentence construction is possible only when it is integrated into the intonation unit of the main clause. This is the case in (27), where the main clause and the before clause form one single intonation unit: the before clause in this structure can serve as focus of the assertion in the main clause, with the proposition of that main clause as a presupposition. When the secondary clause belongs to a separate intonation unit, on the other hand, focused status is impossible because in that case the main clause assigns focus WITHIN its own intonation unit. This is the case in (28), where the main clause and the before clause each have their own intonation unit. The fact that the main clause in this structure forms a separate intonation unit from the secondary clause also implies that it has its own focuspresupposition structure separate from the secondary clause: the question in (28) is about whether or not the interlocutor will go to the pub, and not about when this will happen. Unlike in (27), the temporal specification in the before clause is added as an afterthought in a separate intonation unit and does not serve as focus of the speech act in the main clause.

Taken together, the different properties that play a role in the distinction between [+ Scope] and [-Scope] are summarized in Table 2.

\subsection{The relevance of initial position}

The analysis presented in the previous section actually applies only to clauses in final position. As with the first parameter, clauses in initial position have a special status with respect to the parameter of scope, in that they have a clear preference for detached construal (-Scope), with integrated construal $(+$ Scope $)$ as a marked option. There are various types of evidence for this preference. On the one hand, initial clauses with integrated construal are characterized by a restricted distribution, a marked 
Table 2. The parameter of $[+/-$ Scope $]$

\begin{tabular}{|c|c|c|c|}
\hline & & \multicolumn{2}{|c|}{ Scope } \\
\hline \multicolumn{2}{|c|}{ although, and, but, for, whereas } & \multirow{2}{*}{\multicolumn{2}{|c|}{-}} \\
\hline \multirow[t]{2}{*}{ as, since, when, while } & $\begin{array}{l}\text { Contrastive } \\
\text { Justificational }\end{array}$ & & \\
\hline & Temporal & \multirow{2}{*}{$\stackrel{+}{\text { (inton. integration) }}$} & \multirow{2}{*}{$\stackrel{-}{\text { (inton. detachment) }}$} \\
\hline \multicolumn{2}{|c|}{$\begin{array}{l}\text { after, as, as long as, before, if, once, } \\
\text { so that }\end{array}$} & & \\
\hline
\end{tabular}

intonational encoding, and a low text frequency, which clearly brings out the marked nature of this configuration. On the other hand, the special status of initial clauses in terms of scope structure is also confirmed by other features such as their behavior with respect to quantifiers and other logical operators in the main clause (see, for instance, de Swart 1999).

First of all, integrated construal for initial clauses is restricted in terms of distribution: it is available only for constructions with declarative main clauses, but not with interrogative or imperative main clauses. Compare, for instance, the interrogative structure with a final while clause in (29) with the interrogative structure with an initial while clause in (30).

(29) I think it's very important to measure when and where things occurred. Did they occur when you're a young person, in your formative years, or did they occur while you were a senior official in the federal government? (CB)

= "was that the time $[$ focus] when these things happened [presupposition]?"

(30) While you were a senior official in the federal government, did these things occur?

$\neq$ "was that the time $[$ focus] when these things happened [presupposition]?"

The structure with the final while clause easily allows an interpretation where the while clause is the focus of the interrogative: the speaker in (29) presupposes that some bad things happened, and asks whether they happened while the interlocutor was a senior official. If we move the while clause to initial position, however, this interpretation is no longer available. A structure like (30) cannot be interpreted as presupposing that "these things happened" and asking when they happened: instead, the interrogative in a structure with an initial clause focuses on the SoA de- 
scribed in that main clause ("did these things happen or not?"), with the initial clause providing a temporal frame for this question.

Thus, the detached interpretation for initial adverbial structures is distributionally restricted to constructions with declarative main clauses, as in examples like (31) below (see also Givón 1975: 196-197; Chafe 1984: 439-441; Bickel 1993: 46-48 on this construction), where the initial temporal clause when I speak in public serves as focus, as indicated by the presence of the focus particle especially and by the discursively presupposed status of its main clause (the need to include everyone in the debate, which is mentioned in the immediately preceding sentence).

(31) It is better for me to go ahead slowly and carry everyone with me than to hurry along and cause dissension. Especially when I speak in public I must show that I love all my sheep, like a good shepherd. (CB)

Apart from the argument from distribution, there are two additional arguments for the marked status of initial clauses with integrated construal. On the one hand, this structure is intonationally distinguished from its detached counterparts with a marked fall-rise intonation pattern on the secondary clause, similar to the one found with fronted objects (see Halliday 1967b: 41; Quirk et al. 1985: 1375-1378). On the other hand, the structure is also characterized by a very low frequency in text counts: a text study carried out by Chafe (1984: 439), for instance, reports three instances for a total corpus of 200 adverbial clauses.

In addition to the various markedness arguments, there is another category of arguments that shows the preference for detachment in initial adverbial clauses. As pointed out by de Swart (1999), initial adverbial clauses also behave differently from their final counterparts with respect to the interpretation of quantifiers in the main clause: final adverbial clauses can be interpreted as falling within the scope of quantifiers, whereas initial adverbial clauses cannot. Thus, for instance, the construction with initial when clause in (32a) only allows an interpretation where the birth of a calf somewhere in the village is an occasion for all the farmers to gather in the pub, that is, where the when clause is not in the scope of the quantifier every. The construction with final when clause in (32b), on the other hand, also has an interpretation where the adverbial clause is in the scope of the distributive meaning of the quantifier every in every farmer: in addition to the interpretation of (32a), (32b) can also be interpreted as meaning that farmers celebrate the birth of a new calf on their farm with a visit to the pub, that is, on the different farms in the village it is the custom for the farmer to go and have a beer when he has a new calf, but that not all farmers in the village gather to celebrate this. 
This interpretation is not available for the construction with the initial when clause in (32a).

(32) a. When a new calf is born, every farmer in the village goes to the pub.

b. Every farmer in the village goes to the pub when a new calf is born.

Thus, the behavior of quantifiers in the main clause with respect to adverbial clauses strongly resembles the behavior of illocutionary operators, and basically confirms the preference for detached construal in initial adverbial clauses. In combination with the markedness argument adduced at the beginning of the section, this shows that initial clauses also have a special status with respect to the parameter of scope. Both values are actually possible, but there is a clear difference in markedness between the two options, with a strong preference for detached construal (- Scope).

It might be objected at this point that the quantifier criterion actually reflects a restriction to detached construal rather than a preference, since the initial when clause in (32a) does not allow the quantifier-bound reading at all. As rightly pointed out by Shaer (2003), however, the behavior of quantifiers is not always as straightforward as it seems to be in (32) above, and sometimes diverges from the behavior of illocutionary operators: given the right context, initial clauses that are detached in terms of illocution (as reflected in intonational detachment) can still be bound to quantifiers in the main clause (see the argument in Shaer 2003: section $1.1,2)$. This shows that the behavior of quantifiers basically belongs to a different level of analysis, and that the parallelism with criteria of illocutionary organization is probably a consequence of a default coalignment between illocutionary and semantic organization, in the sense that illocutionary detachment typically but not necessarily goes hand in hand with semantic detachment. Given that this is only a default correlation, the behavior of quantifiers cannot be used as a criterion in its own right, but only as evidence that indirectly confirms the more basic illocution-related criteria.

\section{Relation between the parameters}

\subsection{In general}

The two parameters discussed in the previous sections both represent aspects of illocutionary organization within the complex sentence construction, but in different structural locations. The parameter of $[+/-$ Speech 
Act] operationalizes the INTERNAL illocutionary structure of the secondary clause: does the secondary clause have an illocutionary value of its own within the clause combination or not? The parameter of $[+/-$ Scope], on the other hand, operationalizes the RELATION of the secondary clause to the illocutionary structure of the main clause: can the secondary clause fall within the scope of the illocutionary operators in the main clause or not?

On the one hand, the functional relation between the two parameters implies that not all theoretically possible combinations of values are actually found: specifically, a construction cannot at the same time have a value of $[+$ Scope $]$ and a value of $[+$ Speech Act $]$. A positive value for scope implies that the secondary clause falls within the scope of the illocution in the main clause, whereas a positive value for speech act implies that the secondary clause has an illocutionary value of its own, independent of that of the main clause. These two configurations are of course incompatible. A clause cannot have an illocutionary value of its own while at the same time falling within the scope of the illocution of the main clause: the former configuration implies separate illocutionary status, whereas the latter configuration implies construal as part of the propositional content of the illocution of the main clause. For a clause in a complex sentence construction to have an illocutionary value of its own, it must function independently from the illocutionary structure of the other clause, that is, it must have a negative value for the parameter of scope.

Apart from this restriction, however, the values for the two parameters can be freely combined, which leads to a typology of three basic types of complex sentence constructions, as shown in Table 3. In the first type, illustrated in (33) below, both main clause and secondary clause have their own illocutionary value, and the secondary clause does not fall within the scope of the illocutionary operators of the main clause. In the second type, illustrated in (34) below, the secondary clause does not have any illocutionary value of its own and falls within the scope of the illocutionary operators of its main clause. The third type, illustrated in (35) below, lies in between these two extremes in terms of illocutionary structure: the

Table 3. Combining the parameters

\begin{tabular}{|c|c|c|}
\hline & - Speech Act & + Speech Act \\
\hline - Scope & $(35)$ & (33) \\
\hline + Scope & $(34)$ & \\
\hline
\end{tabular}


Table 4. The special status of initial clauses

\begin{tabular}{|l|c|c|}
\hline & Speech act & Scope \\
\hline Initial & - & $-/(+)$ \\
\hline Final & $+/-$ & $+/-$ \\
\hline
\end{tabular}

secondary clause does not have any illocutionary value in this construction, but unlike in (33) it still does not fall within the scope of the illocutionary operators of its main clause. The precise functional value of this last construction type, which is usually overlooked in the literature, will be discussed in more detail in section 5 .

(33) Yeah, I know that, the first price has gone up, but does that mean all of them go up? (IC)

(34) I had to face the questions, what will be the price of my denial? Do I love God because God blesses? (IC)

(35) Do you wanna ... erm go for a qluick one \# before it clloses \# . yleah \# . before it clloses \# (IC)

\subsection{The status of initial clauses}

The analysis in the previous sections shows that initial clauses are different from final clauses in that they have a special status with respect to the parameters of speech-act value and scope. Whereas final clauses can take both values for both parameters, initial clauses invariably take a value of [-Speech Act], and preferably take a value of [-Scope], as summarized in Table 4.

Given the special properties of initial adverbial clauses in terms of the parameters of speech act and scope, they actually single out one cell in the table of clause combining constructions, as illustrated in Table 5: initial clauses form a separate construction type within the domain of

Table 5. Initial clauses as a specific construction type

\begin{tabular}{|l|l|l|} 
& - Speech Act & + Speech Act \\
\hline - Scope & & \\
\hline + Scope & & \multicolumn{1}{|}{} \\
\cline { 1 - 2 } & &
\end{tabular}


clause combining in English, which takes the values [- Speech Act] and [-Scope], irrespective of the conjunction that introduces the secondary clause. In the following sections, I will argue that it is precisely this configuration of values that can explain why initial position goes hand in hand with discourse-organizing function, and why it can be used to test for subordination.

\section{Explanation for the discursive characteristics of initial position}

As mentioned in the introduction, it has often been observed in the literature on clause combining that there is a correlation between position and discourse function, in that initial clauses typically have a discourseorganizing function, for instance by linking back to a preceding stretch of discourse or serving as a frame for upcoming discourse, whereas final clauses typically have a local function, providing adverbial specification for the SoA described in the main clause. In this section, I will argue that the specific constructional features of initial clauses described in the previous sections can be used to explain why initial position typically goes hand in hand with a discourse-organizing function. In addition, I will also show that the correlation between final position and local function is overstated in the literature, and that there is actually only one subtype of final clause that has a specifically local function.

\subsection{Speech-act value and backgrounding}

As argued in section 2, initial clauses have a special status in that they consistently take a value of [- Speech Act], that is, they do not constitute a speech act within the complex sentence construction. In this section, I will show that it is precisely this property that makes them suitable for discourse-organizing functions. Consider, for instance, the distinction between the but clause in (36), which functions as a separate speech act within the complex sentence, and the while clause in (37), which does not.

(36) Do enjoy a reasonable amount of alcohol, but do not drink solidly from breakfast champagne to late-night malt. Take a break at some point and drink water and tea. Agree on this before too many bottles have been consumed, and make it clear that nobody is trying to spoil the fun. (CB)

(37) Tom's tumble came at $4.30 \mathrm{pm}$. He had to endure an agonising seven hours before he got medical help. The actor recalled: We 
didn't arrive at the hospital until after 11 o'clock. There are only two ambulances in the Clifden area to cover 400 square miles and the local one was busy. While we waited on the ambulance, my wife arrived on the scene from our holiday home in Leenane and kept me warm with hot water bottles and blankets. $(\mathrm{CB})$

As already mentioned in section 2, the difference in illocutionary structure between these two examples is reflected in the divergent availability of the paradigm of basic clause types. The central function of these clause types is to encode negotiation between speaker and interlocutor: they serve to affirm, call into question, deny, order, or request. In this perspective, the behavior of the basic clause types is a good measure of the interactive prominence of a proposition. Presence of a full paradigm of basic clause types reflects the status of a proposition as part of the material that is negotiated between speaker and interlocutor on the foreground of interaction. In a two-speech-act structure like (36), the proposition in the but clause is just as much part of the foreground of interaction as the proposition in the first one: both the need to drink and the need not to overdo it are subject to negotiation between speaker and interlocutor (here in deontic terms). Neutralization of the paradigm of basic clause types, on the other hand, reflects the status of a proposition as part of the background of interaction, as material that is interactionally "deactivated." In a structure like (37), the proposition in the while clause is not subject to negotiation between speaker and interlocutor: the question whether or not the victim is waiting for the ambulance is not an interactively relevant issue in (37) the way the need not to overdo it is in (36). This proposition represents interactionally "deactivated" material, and it is precisely this deactivated status that makes it suitable for doing different types of discourse-organizational work.

Discourse organization is not about negotiation between speaker and interlocutor (is something the case or not, is it necessary or not, etc.): instead, discourse-organizing propositions take care of other functions in the background of interaction, like providing frames for what is interactively central, or smoothing the flow of discourse. The former function is illustrated in (30) above, where the while clause provides a frame that defines the time span for which the question asked by the speaker is relevant. The question whether or not the interlocutor was a senior official is not an issue in (30): what is at issue in the interaction is the question whether bad things happened, and the while clause defines a temporal frame with respect to which the speaker is asking this question (see further in section 5.2 below on this function). The latter function is illustrated by the while clause in (37): at this point in the development of the 
discourse, waiting for the ambulance is no longer an issue, having been discussed at length in the preceding discourse, but mentioning it in the form of a temporal adverbial helps to smooth the transition of the scene from the delay of the ambulance to the arrival of the victim's wife.

In this sense, the absence of an illocutionary value in initial clauses is one factor that makes them suitable for taking up discourse-organizing functions. Still, this is only a necessary but not a sufficient condition for discourse-organizing functions. Structures like the while clause in (38) below are characterized by absence of an illocutionary value just like their counterparts in (37), but unlike these counterparts they crucially do NOT have a discourse-organizing function but rather a local function, in this case describing the temporal circumstances of its immediate main clause, that is, specifying when precisely the instrument was stolen.

"Whoever took this violin is ultimately stealing from the old, they're stealing from handicapped kids and they're stealing from the blind," said Michael Miller, a court-appointed lawyer who was investigating Morini's estate. The FBI and the police department believe the instrument was probably stolen while Morini was in hospital shortly before her death. (CB)

Thus, structures like (38) clearly show that a value of [-Speech Act] cannot be the only factor behind the distinction between discourseorganizing function and local function. In the following section, I will argue that scope is the other factor that is needed to provide the explanation: interactionally deactivated clauses can only take up discourseorganizing functions when they are outside the scope of the illocutionary operators of their main clause.

\subsection{Scope and local function}

As argued in section 3, initial clauses are not only distinguished from their final counterparts by a value of [- Speech Act], but they also have a clear preference for detached construal, that is, a value of [-Scope]. In this section, I will show that scope is the second factor we need in order to explain the distinction between local and discourse-organizing function. A value of [-Speech Act] implies that a structure functions in the background of interaction and is therefore suited to do discourse-organizing work, but it crucially depends on the scope structure of a construction whether this background information actually takes part in the largerscale structuring of discourse or functions only locally. 
Specifically, if in a particular construction the secondary clause falls within the scope of the illocutionary operators of its main clause this means that its function will be internal to the speech act encoded in that main clause. The while clause in (39) below, for instance, falls within the scope of the interrogative structure in the main clause, as reflected in the fact that it can serve as its focus. In functional terms, this position within the scope of the interpersonal structure of the main clause means that the while clause in (39) is part of the propositional content of the illocution encoded in that main clause, serving as background material that specifies its temporal circumstances. This is why integrated construal entails a local function: if a secondary clause falls within the scope of the illocutionary operators of its main clause, its function will be internal to the propositional content of the speech act encoded in that main clause.

(39) One of the sisters in the convent is a district nurse and she told me about X [name removed from corpus, JCV] Care and they arranged it for me and came to see me. Did she tell you about it while you were in the hospital or after you'd come back home? (CB)

Given the fact that integrated construal implies a local link for the secondary clause in the construction, detached construal, that is [-Scope], must be regarded as a necessary prerequisite for the secondary clause to have wider discourse-organizational functions rather than the local ones. When a secondary clause functions outside the scope of the illocutionary operators in the main clause, it is not restricted to a purely local function, but can also have nonlocal functions in addition to the strictly local links with its immediate main clause. Thus, for instance, the when clause in (40) does not only describe the temporal circumstances for its immediate main clause, but also has a wider discourse-organizing function, in that it summarizes the description of the preparations in the preceding discourse and thus serves as a discursive bridge to the main clause, which goes on to the actual description of the parcels.

(40) Then she was in the hall, calling upstairs to summon the girls and Randall. David came back and sat down in the living room. Lainey had gone to find paper and pencils to make thank-you lists as they opened the presents. When they were finally set, Lainey declared that Mack got to be first, because he was the one who'd had to go to the hospital. Mack blushed and then asked for the package that he'd checked on earlier. (CB)

In cases like (40), the wider discourse-organizing links seem to coexist with more local links to the immediate main clause, but in other cases the local function of specifying the circumstances of the main clause dis- 
appears completely. ${ }^{11}$ This is illustrated, for instance, in the contrast between (41a) and (41b) below (adapted from Klein 1994: 163-164). Whereas the final when clause in (41b) can be said to specify the temporal circumstances of the leaving, this is no longer the case in its initial counterpart in (41a): instead of specifying the time of leaving, the when clause specifies "the time span to which the speaker's claim on this occasion is confined" (Klein 1994: 4). This implies that the subject may have left earlier than the time specified by the when clause: the only thing the temporal adverbial specifies in (41a) is the time for which the assertion is valid, and this need not coincide with the actual time of leaving (compare When I got back from school, he had left. My brother told me he had left four hours earlier). Examples like these further confirm the role of illocutionary scope as an explanatory principle in distinguishing between local and nonlocal functions: an adverbial clause that falls within the scope of the illocutionary operators of its main clause modifies the propositional content in that main clause, as in (one interpretation of) (41b), whereas an adverbial clause outside the scope of these operators can also relate to the illocutionary value of the main clause as such, as in (41a), where it specifies the time span for which the assertion in the main clause is valid rather than describing the temporal circumstances of the SoA (see also Verstraete 1998 on this principle).

(41) (adapted from Klein 1994: 163)

a. When I got back from school, he had left.

b. He had left when I got back from school.

In conclusion, therefore, a value of [-Scope] can be regarded as the second prerequisite for a secondary clause to take up a discourse-organizing function. Again, this prerequisite is not sufficient by itself, since there are also detached [-Scope] structures with a value of [+Speech Act], as in (33) above, where the secondary clause does not have any background function at all but is part of the foreground of speaker-interlocutor interaction. Only in combination do the values of [-Speech Act] and [-Scope] define the necessary and sufficient prerequisites for a secondary clause to take up a discourse-organizing function in addition to the purely local links that tie it to its immediate main clause.

\subsection{Conclusions}

Taken together, the values of [-Scope] and [-Speech Act] define the basic constructional prerequisites for a secondary clause to take up a dis- 
course-organizing function: the interactional deactivation associated with the absence of an illocutionary value ensures that the structure in question operates in the background of speaker-interlocutor interaction, and the position outside the scope of the illocutionary operators of the main clause ensures that this background information can function in a wider discourse context.

This analysis also allows us to assess the claims found in the literature about the correlation between position and function. On the one hand, it can help to explain the tendency for initial clauses to have discourseorganizing functions: the discussion in sections $2-4$ has shown that initial clauses constitute a separate construction type, in that they always have a value of $\left[-\right.$ Speech Act] and that they have a clear preference ${ }^{12}$ for a value of $[-$ Scope]. This implies that initial clauses inherently have the basic constructional prerequisites for discourse-organizing functions: they operate in the background of interaction, and they are free to take up wider links with the surrounding discourse context. On the other hand, the analysis also shows that a correlation between final position and local function is something of an overgeneralization. From a constructional perspective, there is only one type of construction where the final clause is necessarily local, more specifically when it falls within the scope of the illocutionary operators in the main clause. This is not the only type of final clause, however: final clauses can also be outside the scope of the illocutionary operators in the main clause (see Table 4 above), and in some cases they are even characterized by absence of an illocutionary value just like the typical initial clause, as in (42) below.

(42) I'm gonna get my phloto\#, todlay\# will you be here tomlorrow\# yleah\# are there any rude ones of mle\# I dunnlo\# I haven't sleen 'em y/et\# cos Jo got a picture of my hlead\#, when I was slleeping\# (IC)

Given that they have the basic constructional prerequisites, such final clauses can take up discourse-organizing functions just like initial ones: thus, for instance, the when clause in (42) serves as an afterthought that reframes the preceding assertion, indicating how it is relevant to the preceding discourse context, more particularly the inquiry about rude pictures. Structures like these clearly show that final secondary clauses cannot be generally associated with local functions and contrasted with the discourse-organizational functions of initial clauses, as also argued in a different context by Klein (1994: 164): given the right values for the parameters of speech act and scope, final adverbial clauses can have discourse-organizing functions just like their initial counterparts. 
Table 6. Position, grammatical features, and function

\begin{tabular}{|c|c|c|c|c|}
\hline \multirow{2}{*}{$\begin{array}{l}\text { Grammatical } \\
\text { features }\end{array}$} & \multicolumn{3}{|c|}{ [-Speech act $]$} & {$[+$ Speech act $]$} \\
\hline & \multicolumn{2}{|c|}{ [-Scope] } & [+ Scope $]$ & [-Scope] \\
\hline Position & Initial & Final & & \\
\hline \multirow{2}{*}{ Function } & Discou & anizing & Local & \multirow{2}{*}{ Foreground } \\
\hline & \multicolumn{3}{|c|}{ Background } & \\
\hline
\end{tabular}

In conclusion, therefore, the relation between position and function can be summarized as in Table 6. Leaving aside the marginal construction type where initial clauses have a value of $[+$ Scope $]$, the correlations between initial position and discourse-organizing function, and between final position and local function can be restated more accurately as follows. Given that initial position is always [-Speech Act] and generally also detached (-Scope), a secondary clause in this position will generally also have a discourse-organizing function. Given that final position is the only position that generally allows integrated construal (+ Scope), secondary clauses with a local function will generally also be in final position. The converse is not the case, however, because there are also secondary clauses in final position that do not have a purely local role, but also take up discourse-organizing functions.

\section{Explanation for the syntactic characteristics of initial position}

The second characteristic of initial position which we set out to explore in this study is its use as a criterion to distinguish between coordinate and subordinate constructions. Subordinate constructions are traditionally defined and distinguished from their coordinate counterparts by their ability to move the secondary clause into initial position, that is, before the main clause. One question that is not often dealt with in the literature, however, is WHY the initial position can be used as a criterion. In this section, I will argue that the grammatical features discussed in sections 2-4 are not only useful in elucidating the relation between position and function, but that they can also be used to throw some more light on the nature of subordination and the use of initial position as a syntactic criterion. 


\subsection{Initial position and the coordination-subordination distinction}

The question wHY initial position can be used as a formal criterion to distinguish between coordinate and subordinate constructions has not often been addressed in the literature, but Halliday (1994 [1985]: 222-223) suggests that this is a natural consequence of the dominant-dependent organization of subordinate constructions: given that main clause and subordinate clause are inherently specified as dominant and dependent, the two clauses can appear in any surface order without affecting this dominance-dependence organization. This type of explanation merely shifts the problem, however, because it does not explain what it actually means for a clause to be "dominant" or "dependent" within a complex sentence construction, and how this can be determined independently from their ability to occur in any surface order. What we need is an independent feature that can provide a functional definition for the notions of "dominant" and "dependent," and connect them with the formal criterion of preposability. In this section, I will show that the feature of [-Speech Act] discussed in section 2 can be used to provide a functional account of subordination and link this with the formal criterion of preposing.

In section 2 it was shown that there is a basic distinction between complex sentence constructions where both clauses have an illocutionary value, like (43) below, and constructions where one clause lacks an illocutionary value, like (44) below, as reflected in the paradigmatic restriction of the after clause to the declarative clause type. On a more general level, the former construction is characterized by a balance in illocutionary structure, whereas the latter construction is characterized by a fundamental imbalance between main clause and secondary clause in terms of illocutionary structure. Functionally, the illocutionary balance in constructions like (43) can be linked to the "independence" and "equality of status" that has traditionally been attributed to coordinate constructions (see for instance Lyons 1968: 178; Quirk et al. 1985: 987; Halliday 1994 [1985]: 221): the clauses in (43) are equal and independent in that they each constitute a speech act, just like independent main clauses. On the other hand, the illocutionary imbalance in constructions like (44) can be linked to the "inequality" that has traditionally been associated with subordinate constructions: the two clauses are fundamentally unequal in that only one of them constitutes a speech act and is central to speakerinterlocutor interaction, whereas the other does not constitute a speech act and functions in the background of interaction.

(43) Do make an effort with the costume, but don't make other children and parents feel inadequate. (CB) 
(44) I played the video for some people that didn't even know what it was. And after they said they liked it, they were almost sorry because they found it was classical music. (CB)

The idea of linking the coordinate-subordinate distinction with a distinction in illocutionary structure of the secondary clause is of course not new: there is a long tradition in functional treatments of clause combining to define the distinction in terms of illocutionary force (see, for instance, Bossong 1979; Foley and Van Valin 1984; Hengeveld 1998; Cristofaro 1998). An important piece of evidence that has not been explored so far, however, is the way this functional account can also provide an explanation for the formal criteria that have traditionally been used to support the distinction. In this case, a functional definition of the coordinatesubordinate distinction in terms of illocutionary structure can also explain WHY initial position can be used as a criterion to distinguish between the two categories. The analysis in section 2 shows that initial position is inherently characterized by absence of illocutionary force, as formally reflected in the fact that it does not allow any nondeclarative clause types, not even for conjunctions that do allow interrogative or imperative structures in final position. This is precisely what makes it a good context to test the coordinate or subordinate status of a particular structure: if a particular clause can be moved into initial position, this shows at the same time that it can be construed with a value of [-Speech Act], that is, as a backgrounded proposition within the complex sentence construction. Further evidence for the usefulness of this approach to the coordinatesubordinate definition is outlined in Verstraete (2004), where it is argued that it can also account for the use of word order criteria (V2 versus V-final) for subordinate status in other Germanic languages like German and Dutch.

\subsection{Different types of subordination}

The functional interpretation of the coordinate-subordinate distinction discussed in the previous section is not the only one that has been proposed: in fact, there are two major traditions of defining the distinction in the literature. The definition in the previous section fits in with the more general idea that subordinate clauses are somehow less PROMINENT within the complex sentence construction, an idea that has been further specified in terms of presupposition (Keenan 1971: 45-47; Winter 1982), challengeability (Givón 1982: 101-102) or figure-ground organization (Townsend and Bever 1977; Talmy 1978). ${ }^{13}$ Another very widespread 
interpretation of the distinction is that subordinate clauses are somehow INTEGRATED into their main clause, a concept which is specified either in terms of constituency (Jespersen 1924: 103-106; Brøndal 1972 [1937]: 2627; Foley and Van Valin 1984: 239-241; Quirk et al. 1985: 987), intonation (Chafe 1984, 1988), or semantic closeness (Givón 1980).

From the perspective of the present analysis, the issues of prominence and integration are not simply two alternative perspectives on one and the same category of subordination, but two formally and functionally distinct parameters. As argued in the previous section, the parameter of illocutionary value provides a measure of prominence: clauses that constitute a speech act are interactionally prominent in the complex sentence construction, whereas clauses that do not constitute a speech act belong to the background of interaction. The category of subordination that is defined in terms of prominence is not internally homogeneous, however: it covers at least two distinct construction types, which share the feature of absence of illocutionary force in the secondary clause, but which are distinct in terms of scope structures. Thus, for instance, the before clause in (45) and (46) is characterized by absence of illocutionary force, but in (45) it falls within the scope of the question in the main clause, whereas in (46) it falls outside the scope of this question.

(45) Now I notice you were at Lewis's. Now did you go to Lewis's before you went to university? (CB)

(46) I began by asking him about that remark that "diplomacy must be given every chance." Now, just before you said that, did you grin to yourself and think $[\ldots]$ ? (CB)

In this sense, the parameter of scope can be said to provide a secondary measure of integration for the category characterized by lack of prominence. A structure with a value of [+Scope] like (45) is integrated into its main clause because it falls within the scope of the speech act encoded in that main clause and thus is part of the propositional content of that main clause. A structure with a value of [- Scope] like (46), on the other hand, is detached from its main clause in that it does not form one single speech act with that main clause, but functions outside the scope of its illocutionary value.

From this perspective, the two traditions in the definition of subordination should, at least for the analysis of adverbial constructions, not be regarded as two alternative perspectives on the same category, but rather as defining distinct phenomena. The distinction between constructions like (45) and (46) clearly shows that structures that are subordinate in terms of lack of prominence within the complex sentence construction 
need not necessarily be subordinate in terms of integration with the main clause.

\section{General conclusion}

The central argument developed in this study is that there are two types of illocutionary variation according to which complex sentence constructions can be classified, one relating to the internal illocutionary structure of the secondary clause, and another relating to the status of the secondary clause with respect to the illocutionary structure of the main clause. In terms of these two parameters, adverbial clauses in initial position can be characterized as a distinct construction type: they do not constitute a separate speech act within the complex sentence construction, and they generally do not fall within the scope of the speech act in their main clause. Functionally, the former characteristic implies that initial clauses are interactionally "deactivated" and backgrounded, whereas the latter characteristic implies that their function is not restricted to purely local modification of their immediate main clause.

Taken together, these two constructional features can be used to motivate the correlation between initial position, wide discursive function and subordination that has often been observed in the literature but has usually been left unexplained. In addition, the construction-oriented approach proposed in this study also provides a number of corrections and refinements to certain traditional views in the literature. The general correlation between final position and local function, for instance, can be refined from a constructional point of view: only final clauses with the necessary constructional prerequisites in terms of scope structure have a local function. In addition, the analysis can also be used to reassess the status of competing definitions of subordination (relative prominence versus integration) as distinct and hierarchically ordered phenomena rather than as two alternative perspectives on one and the same phenomenon.

The analysis developed in this study also raises a number of questions for further research, for instance concerning its applicability to other domains in English and to cross-linguistic analysis. One question that was not looked at is in how far the framework developed for adverbial clauses can also be extended to nonclausal adverbials (like yesterday or happily). Due to their difference in internal structure, the basic distinction between the two categories seems to lie with the parameter of speech-act value. Unlike their clausal counterparts, nonclausal adverbials obviously cannot take different values for this parameter: because of their nonpredicative nature, expressions like yesterday and honestly cannot form a speech act 
on their own, and are therefore to be classified as [- Speech Act]. With respect to the parameter of scope, however, nonclausal adverbials show the same behavior as their clausal counterparts: they allow both integrated (+ Scope) and detached ( - Scope) construal, and the distinction between the two seems to be linked to the same types of features as with their clausal counterparts, namely lexical polysemy, intonation unit distribution, and position (see the criteria in Greenbaum 1969: 18-25). In this perspective, it is not surprising that the same functional correlations can be found in this domain. Just like with their clausal counterparts, integrated nonclausal adverbials are restricted to illocution-internal SoAmodifying functions (John talked to the police first/honestly), and detached nonclausal adverbials are free to take up discourse-organizing functions (First, John talked to the police [and second, ...]) and illocutionmodifying ones (Honestly, John talked to the police). In this sense, at least the parameter of scope and its functional reflections seem to be generalizable across the domain of adverbials in English, irrespective of differences in internal structure of the adverbial expression.

Beyond the analysis of the adverbials in English, the framework developed in this study may also provide an interesting perspective on the cross-linguistic analysis of adverbial clauses. One thing that is striking about the typology of adverbial clauses is that not all languages allow different positions for adverbials: as shown in Diessel (2001), there are also languages where they are restricted to initial position. From a pure constituent-order perspective, this raises the question how the distinction between local and discourse-organizing functions can be made in these languages, if it is made in the adverbial domain at all. From the perspective of the present analysis, on the other hand, this is not an issue at all: the central point is that what matters for the distinction between local and discourse-organizing function are the constructional parameters that functionally motivate the distinction, and not the formal issue of constituent order as such. In cross-linguistic analysis, a constructional framework will focus on the formal realization of the relevant functional parameters rather than on the issue of position, and typological differences in the position of adverbial clauses will be derived from language-specific differences in the marking of the relevant parameters. It could be speculated, for instance, that the distinction between languages with variable and with fixed position for adverbial clauses correlates with different formal means of marking illocutionary focus: assuming that in English it is the preference for clause-final illocutionary focus that motivates the strong association of local function with final position, languages with a fixed initial position for adverbial clauses may have positionally more variable focus markers to do the same job. This is of course largely spec- 
ulative, but the important point is that from the perspective of this study, the motivating functional parameters take precedence over the constituent-order facts, which merely reflect the language-specific formal properties of the functional parameters.

Received 5 November 2002

Revised version received

5 February 2003
Fund for Scientific Research - Flanders
University of Leuven

\title{
Appendix. Corpora
}

\author{
CB COBUILD Bank of English \\ COLT Corpus of London Teenage language \\ IC ICAME Collection of English Language Corpora
}

\section{Notes}

1. Part of this material was presented in seminars at the universities of Aarhus, Utrecht, Lille and Kortrijk, and at the SLE conference in Leuven. I am grateful to Hans Arndt, Bert Cappelle, Kristin Davidse, Renaat Declerck, Ilse Depraetere, Flip Droste, Patrick Goethals, Liliane Haegeman, Lachlan Mackenzie, Bill McGregor, Henk Pander Maat, Jan Rijkhoff and Ted Sanders for their comments on these and other occasions. I would also like to thank two anonymous Linguistics reviewers for their comments and suggestions, as well as Ben Shaer for providing me with copies of unpublished work. The usual disclaimers apply. Correspondence address: Department of Linguistics, University of Leuven, Blijde-Inkomststraat 21, 3000 Leuven, Belgium. E-mail: jean-christophe.verstraete@arts.kuleuven.ac.be.

2. I will use the term "adverbial clause" as a convenient traditional label, but in fact the function of this type of clause is not always to modify the verb or VP of its main clause. It can also relate to other aspects of the main clause, like its illocutionary force (see Sweetser 1990; Verstraete 1998), and it can have additional links beyond its immediate main clause, as will be discussed in this study.

3. The adverbial clauses under discussion are underlined. The examples used in this study are taken from the Cobuild corpus (CB) and the ICAME collection of English corpora (IC).

4. In contexts that generalize over adverbial-subordinate and coordinate structures, I will use the more general term "secondary clause" to refer to the clause introduced by the conjunction.

5. Clauses introduced by so that are slightly different from the other structures in this category in that initial position is available only for the purpose interpretation (e.g. So that you can really make the most of these opportunities, we have included a second application form for your partner or another member of your immediate family [CB]), but not for the result interpretation. This is probably due to the strong sequentiality and factuality implied by the meaning of result clauses, which requires iconic ordering of main clause and secondary clause. The semantic motivation for this restriction is con- 
firmed by Diessel's (2001) cross-linguistic study of ordering tendencies, which shows that result clauses are cross-linguistically ranked high on the scale of typically postposed structures, even in languages which generally allow both initial and final position for adverbial clauses.

6. Negation is added here in order to take into account the possibility of a "rhetorical" interpretation for the interrogative. Some conjunctions allow only rhetorical interpretations for nondeclarative clause types: these structures still constitute a speech act, but with an interpretational restriction to assertive illocutionary force. See further in Lakoff (1984) and Verstraete (2004) on this phenomenon.

7. The status of final clauses, and its relevance for the claims found in the literature about a correlation with local function, will be discussed in section 5.3.

8. The fact that nondeclarative clause types typically receive rhetorical interpretations in because and although clauses, as is the case with the wh interrogatives in (19) and (20), is due to the argumentative nature of the conjunctions, as argued in more detail in Verstraete (2004).

9. The link between focus on the secondary clause and presupposition for the main clause is crucial here: for coordinators like and, but, and or, the focus of interrogation or modalization marked on the main clause CAN actually extend to the secondary clause, in elliptical structures like Did they round you all up AND - AND MAKE YOU GO IN THE BASEMENT THERE? (CB), but in these cases the main clause equally serves as focus and is not presupposed. This is a different type of configuration from the focus-presupposition configurations illustrated in the examples above, and therefore cannot be taken as evidence for the value [+ Scope]. See further in Tikkanen $(1987,1995)$ on the distinction between coordinative and subordinative scope structure.

10. Examples with prosodic transcription are taken from the COLT (Corpus of London Teenage language) subsection of the ICAME corpus collection (IC). The following transcription conventions are used: \# marks intonation unit boundaries, $\backslash, /,-, \vee$, and $\wedge$ indicate the location of the nuclear accent and the nature of the intonation contour, respectively falling, rising, level, falling-rising, and rising-falling.

11. I am grateful to a reviewer for pointing this out to me.

12. As shown in section 3, there is also a marked construction type where the initial clause has a value of [+Scope], illustrated with example (31) above. This type actually confirms the role of scope structure in distinguishing between local and discursive function, because it constitutes an exception to the general correlation between initial position and discursive function. This type of initial clause does not have a discourse-organizing function, but rather a purely local relation to its immediate main clause: the focus in (31), for instance, is on the precise temporal location of the SoA in the main clause, that is, the circumstances when it is most important to include everyone in the community.

13. The relation between these concepts will not be further elaborated in this paper, as the focus is on the two major categories of definitions rather than on specific subtypes. See further in Verstraete (2002: 175-204) on the relation between those concepts.

\section{References}

Bickel, Balthasar (1993). Belhare subordination and the theory of topic. In Studies in Clause Linkage. Papers from the First Köln-Zurich Workshop, Karen Ebert (ed.), 23-55. Zurich: Seminar für allgemeine Sprachwissenschaft.

Bossong, Georg (1979). Typologie der Hypotaxe. Folia Linguistica 13, 33-54. 
Brøndal, Viggo (1972 [1937]). The problem of hypotaxis. In Syntactic Theory, vol. 1: Structuralist, Fred Householder (ed.), 23-30. Harmondsworth: Penguin.

Chafe, Wallace (1984). How people use adverbial clauses. Berkeley Linguistics Society 10, 437-449.

- (1988). Linking intonation units in spoken English. In Clause Combining in Grammar and Discourse, John Haiman and Sandra Thompson (eds.), 1-27. Amsterdam: Benjamins.

Cristofaro, Sonia (1998). Deranking and balancing in different subordination relations: a typological study. Sprachtypologie und Universalienforschung 51, 3-42.

de Swart, Henriëtte (1999). Position and meaning: time adverbials in context. In Focus: Linguistic, Cognitive and Computational Perspectives, Peter Bosch and Rob van der Sandt (eds.), 336-361. Cambridge: Cambridge University Press.

Diessel, Holger (2001). The ordering distribution of main and adverbial clauses. A typological study. Language 77, 433-455.

Foley, William; and Van Valin, Robert (1984). Functional Syntax and Universal Grammar. Cambridge: Cambridge University Press.

Ford, Cecilia (1993). Grammar in Interaction. Adverbial Clauses in American English Conversation. Cambridge: Cambridge University Press.

Givón, Talmy (1975). Focus and the scope of assertion: some Bantu evidence. Studies in African Linguistics 6, 185-205.

- (1980). The binding hierarchy and the typology of complements. Studies in Language 4, $333-377$.

- (1982). Logic vs. pragmatics with human language as the referee. Toward an empirically viable epistemology. Journal of Pragmatics 6, 81-133.

-(1990). Syntax. A Functional-Typological Introduction, vol. 2. Amsterdam: Benjamins.

Goethals, Patrick (2002). Las Conjunciones Causales Explicativas en Castellano. Un Estudio Semiótico-lingüístico. Leuven: Peeters.

Greenbaum, Sidney (1969). Studies in English Adverbial Usage. London: Longman.

Halliday, Michael (1967a). Notes on transitivity and theme in English. Part 2. Journal of Linguistics 3, 177-274.

-(1967b). Intonation and Grammar in British English. The Hague: Mouton.

-(1994 [1985]). An Introduction to Functional Grammar, 2nd ed. London: Arnold.

Hengeveld, Kees (1998). Adverbial clauses in the languages of Europe. In Adverbial Constructions in the Languages of Europe, Johan van der Auwera (ed.), 335-419. Berlin: Mouton de Gruyter.

Jespersen, Otto (1924). The Philosophy of Grammar. London: Allen \& Unwin.

Keenan, Edward (1971). Two kinds of presupposition in natural language. In Studies in Linguistic Semantics, Charles Fillmore and Terence Langendoen (eds.), 44-52. New York: Holt, Rinehart \& Winston.

Klein, Wolfgang (1994). Time in Language. London: Routledge.

Lakoff, George (1984). Performative subordinate clauses. Berkeley Linguistics Society 10, 472-480.

Lyons, John (1968). Introduction to Theoretical Linguistics. Cambridge: Cambridge University Press.

Quirk, Randolph; Greenbaum, Sidney; Leech, Geoffrey; and Svartvik, Jan (1985). A Comprehensive Grammar of the English Language. London: Longman.

Ramsay, Violeta (1987). The functional distribution of preposed and postposed "if" and "when" clauses in written narrative. In Coherence and Grounding in Discourse, Russell Tomlin (ed.), 383-408. Amsterdam: Benjamins.

Shaer, Benjamin (2003). Left/right contrasts among English temporal adverbials. Unpublished manuscript, Zentrum für allgemeine Sprachwissenschaft. 
Sweetser, Eve (1990). From Etymology to Pragmatics. Metaphorical and Cultural Aspects of Semantic Structure. Cambridge: Cambridge University Press.

Talmy, Leonard (1978). Figure and ground in complex sentences. In Universals of Human Language, vol. 4: Syntax, Joseph Greenberg (ed.), 625-649. Stanford: Stanford University Press.

Thompson, Sandra (1985). Grammar and written discourse: initial vs. final purpose clauses in English. Text 5, 55-84.

Tikkanen, Bertil (1987). Finiteness and non-finiteness as parameters in clause linkage. In The Nordic Languages and Modern Linguistics 6, Pirkko Lilius and Mirja Saari (eds.), 405-419. Helsinki: Helsinki University Press.

- (1995). Burushaski converbs in their South and Central Asian areal context. In Converbs in Cross-Linguistic Perspective, Martin Haspelmath and Ekkehard König (eds.), 487-528. Berlin: Mouton de Gruyter.

Townsend, David; and Bever, Thomas (1977). Main and Subordinate Clauses: A Study in Figure and Ground. Bloomington: Indiana University Linguistics Club.

Traugott, Elizabeth; and König, Ekkehard (1991). The semantics-pragmatics of grammaticalization revisited. In Approaches to Grammaticalization, vol. 1: Focus on Theoretical and Methodological Issues, Elizabeth Traugott and Bernd Heine (eds.), 189-218. Amsterdam: Benjamins.

Verstraete, Jean-Christophe (1998). A semiotic model for the description of levels in conjunction. Functions of Language 5, 179-211.

- (2001). Subjective and objective modality. Journal of Pragmatics 33, 1505-1528.

- (2002). Interpersonal grammar and clause combining in English. Unpublished doctoral dissertation, University of Leuven.

- (2004). Two types of coordination in clause combining. Lingua 114.

Winter, Eugene (1982). Towards a Contextual Grammar of English. The Clause and its Place in the Definition of Sentence. London: Allen and Unwin. 
